\title{
Pain as a symptom of peripheral nerve sheath tumors: clinical significance and future therapeutic directions Michael E Sughrue*1, Jon Levine ${ }^{2}$ and Nicholas M Barbaro ${ }^{1}$
}

\author{
Address: ${ }^{1}$ Department of Neurological Surgery, University of California at San Francisco, 505 Parnassus Ave, San Francisco, California, USA and \\ ${ }^{2}$ Department of Medicine, University of California at San Francisco, 505 Parnassus Ave, San Francisco, California, USA \\ Email: Michael E Sughrue* - Sughruem@neurosurg.ucsf.edu; Jon Levine - Jon.Levine@ucsf.edu; \\ Nicholas M Barbaro - BarbaroN@neurosurg.ucsf.edu \\ * Corresponding author
}

Published: 29 February 2008

Journal of Brachial Plexus and Peripheral Nerve Injury 2008, 3:6 doi:10.1 186/1749-722I-3-

6

This article is available from: http://www.jbppni.com/content/3/I/6

(c) 2008 Sughrue et al; licensee BioMed Central Ltd.

This is an Open Access article distributed under the terms of the Creative Commons Attribution License (http://creativecommons.org/licenses/by/2.0), which permits unrestricted use, distribution, and reproduction in any medium, provided the original work is properly cited.
Received: 24 October 2007

Accepted: 29 February 2008

\begin{abstract}
Tumors arising from the supporting cells of peripheral nerve sheaths are relatively uncommon neoplasms, and as such many clinicians are unfamiliar with the details of their presentation, diagnosis and management. Further, little is known regarding the pathogenesis of these tumors, how they cause symptoms, and how to treat these symptoms. One classic symptom of peripheral nerve tumors is pain, however there has been little formal discussion regarding the significance of pain in this setting. Here we present a brief review of the clinical significance of pain, its relevance in pre-operative planning for the treatment of these tumors, and what is known regarding the molecular mechanisms of pain generation by these tumors.
\end{abstract}

\section{Epidemiology and clinical presentation of peripheral nerve tumors}

Tumors arising from the supporting cells of peripheral nerve sheaths are relatively uncommon neoplasms, and as such many clinicians are unfamiliar with the details of their presentation, diagnosis and management. Further, little is known regarding the pathogenesis of these tumors, how they cause symptoms, and how to treat these symptoms.

Tumors of peripheral nerve are benign in at least $85-90 \%$ of clinically symptomatic cases, and likely a larger percentage of subclinical cases [1]. In normal patients, the majority of these tumors are histologically schwannomas, with lesser percentages made up of other benign lesions such as hemangiomas, ganglion cysts, desmoids, malignant peripheral nerve sheath tumors (MPNST's), and other malignant lesions, such as lymphoma and metas- tases [2]. For patients, with neurofibromatosis type 1 (NF$1)$, the incidence of malignancy is significantly greater: $8-10 \%$ of NF-1 patients will develop an MPNST during their lifetimes, and nearly $50 \%$ of patients with MPNST have NF-1 [3].

The typical presenting signs and symptoms of a peripheral nerve sheath tumor (PNST) involves some combination of a palpable (or radiographically visible) mass involving a peripheral nerve, loss of nerve function, and/or pain $[1,3]$. The etiology and significance of the first two symptoms should be relatively intuitive, for instance, the presence of a significant nerve palsy is likely due to nerve invasion and destruction by the tumor, and is highly suggestive of malignancy. However, the significance of pain in the setting of PNST is significantly less well defined, the mechanisms that cause it are more complex and poorly understood, and the proper tools to specifically or effec- 
tive treat it are currently not available. A brief summary of what is currently known is the topic of the present review.

\section{Pain as a presenting symptom of peripheral nerve tumors}

Of clear importance is the ability to differentiate between benign and malignant lesions as early as possible in the clinical work-up and management of these lesions, as they are treated very differently, and exhibit very different clinical and intraoperative behaviors. Ideally, the probable diagnosis should be known prior to surgery, as malignant tumors are more likely to require aggressive resection and possibly amputation in order to achieve any degree of oncologic control of these aggressive tumors $[2,4,5]$. Despite even aggressive management, the prognosis for these tumors remains poor [5-7]. Benign lesions, in contrast, are often able to be easily resected away from nerve fibers with minimum morbidity $[2,4,5]$. Further, resective surgery is likely to resolve or significantly improve pain in $75-85 \%$ of patients with benign tumors and pre-operative pain [2].

Current evidence suggests that in most cases, benign and malignant lesions can be differentiated pre-operatively based on clinical and radiographic characteristics. Most importantly, while either a palpable/visible mass, nerve palsy, or pain can occur in either benign or malignant tumors, all three are more common and more notable in malignant tumors. For example, rapid enlargement of a nerve mass was found in one study to predict malignant histology have a positive predictive value (PPV) of approximately 95\% [3]. Also, the presence of any neurologic deficit predicts malignancy with a PPV of $73 \%$ which was identical in results published by 2 different groups $[1,3]$. Greater degrees of neurologic deficit (i.e. motor strength less than 3/5), appears to be exclusively a symptom of malignant tumors $(\mathrm{PPV}=100 \%)[1]$.

Less clear is what to make of pain in the setting of a PNST, as approximately $75 \%$ of all patients with PNST (benign or malignant) have pain in some setting, and the positive predictive value of the symptom "pain" to predict malignancy is about $20-30 \%[1,3]$. Far more important is the distinction of pain at rest versus positional pain or pain induced by pressure (i.e. the Tinel's sign). For example, one group reported that pain at rest occurred in nearly all (15/16) patients with MPNST, however only 5/99 (5\%) patients with benign schwannomas or neurofibromas [1]. In contrast, 94/99 of patients with benign tumors had a positive Tinel's test [1]. Thus, further clarification of the character and timing of the pain increases the PPV of the symptom "pain" to $75 \%$, making it a much more useful piece of information in surgical planning.

\section{Potiential mechanisms of pain generation in PNST and future therapeutic directions}

The dichotomy seen clinically between pressure induced pain (which occurs in both benign and malignant tumors) and rest pain (largely a symptom of malignancy) suggests that these types of pain might result from distinct pathophysiologic mechanisms. It follows from this hypothesis that development of optimal therapies for each of these types of pain probably should be directed at different molecular targets. Figure 1 briefly summarizes some of the possible mechanisms involved in neuropathic pain caused by nerve tumors.

\section{Ectopic mechanosensitivity}

The cause of pressure induced nerve pain in the setting of nerve sheath tumors is unknown. The best hypotheses formulated about the cause are extrapolations from work regarding the mechanisms of mechanosensitivity-type pain in Ad- and C-fibers seen in non-neoplastic, mechanosensitive lesions such as neuromas. Mechanosensitivity in these lesions is thought to result from progressive incorporation and buildup of a number of proteins, including mechanosensitive receptors intended for the receptor terminal of a pain receptor, into an ectopic site along an axon [8-11]. To date, the exact molecular transducer of these mechanical pain impulses is unknown.

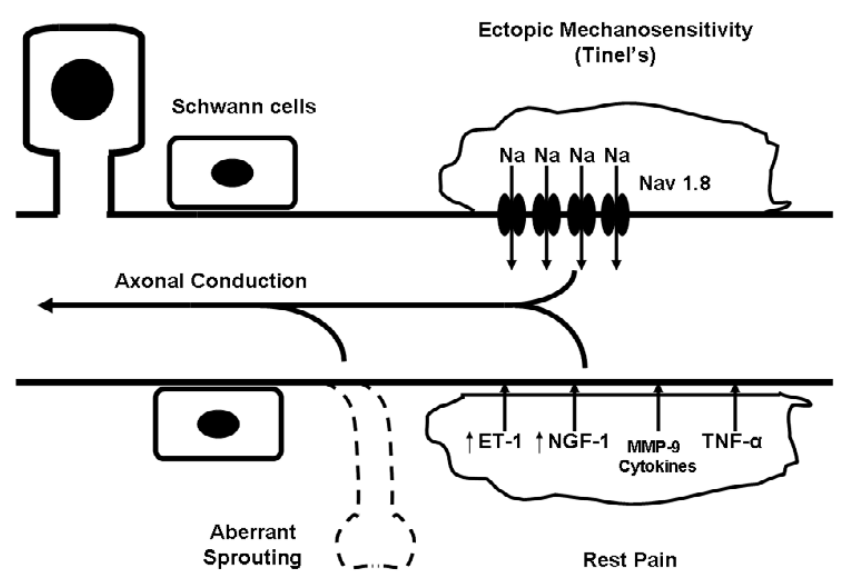

\section{Figure I}

Schematic representation of possible mechanisms of algogenesis in the setting of nerve sheath tumors. Mechanisms depicted include: (A) Ectopic mechanosensitivity possibly due to increase in local concentrations of the $\mathrm{Nav}$ I.4 sodium channel leading to increased axonal transmission in response to mechanical stimulation, (B) Continuous secretion of chemical algogens leading to rest pain in the absence of stimulus, (C) Aberrant axonal sprouting which fire pain stimuli constitutively. 
One protein known to accumulate near areas of axonal compression, which may augment signal transduction, and thus promote the development of a mechanosensitive state, is the tetrodotoxin resistant sodium channel Nav1.8. Clinical studies have demonstrated that Nav1.8 is densely immunolocalized in the region immediately surrounding focal sites of axonal injury, such as neuromas [12-14]. Roza et al. subsequently demonstrated in vitro that Adand C-fibers taken from Nav1.8 null mice were markedly less prone to the development of ectopic mechanosensitivity than nerves taken from wild type mice in an experimental model of neuroma formations, and that these fibers were less likely to develop delayed spontaneous discharges in that same model [15]. The Nav1.8 is a particularly appealing therapeutic target as its expression appears to be largely restricted to peripheral nerves [15], however to date the development of a specific inhibitor has been elusive.

\section{Malignancy-induced nerve pain}

Nerve pain caused by malignant tumors is likely chemical in nature, and results from the release of substances by malignant cells that stimulate chemoreceptive pain fibers, such as $\mathrm{H}^{+}$, proteolytic enzymes, cytokines and growth factors $[1,16,17]$. The later two classes of molecules have the particularly appealing characteristic of potentially specific inhibition as a means of alleviating cancer pain. In many cancers, invasion of the perineurium is necessary for the development of rest pain, suggesting that high periaxonal concentration of the offending algesic substance is required [18]. Given the close proximity of Schwann cells to the axon (originating inside the perineurium), it is likely that any secreted algogen is present in biologically relevant concentrations in the periaxonal space.

One potential algogen, the vasoconstrictive molecule endothelin-1 (ET-1), has been found to be released in high local concentrations in murine fibrosarcoma models of hyperalgesia [19], and was not seen in a non-sarcoma model (melanoma) [19]. Interestingly, local administration of an endothelin-A receptor antagonist significantly reduced the morphine requirement in this model [19]. Similar to fibrosarcomas, MPNST's were also found to have nearly 3-fold increased expression of the ET-1 gene compared to normal schwann cells [20], suggesting that ET-1 upregulation may be a consistent feature of sarcomas in general, and raising the possibility that ET-1 antagonism might be useful in treating MPNST rest pain, though formal in vivo evidence is presently lacking.

Nerve growth factor (NGF) is another algogen that has been commonly implicated as an important cause of both neuropathic and malignant cancer pain. For example, Zhu et al found that human pancreatic cancers with high levels of NGF expression demonstrated more extensive perineu- real invasion, and more severe and refractory pain [18]. Other groups have demonstrated significant reduction of cancer pain with systemic NGF antagonism in murine models $[16,21]$ While NGF may mediate these effects, in part, by inducing cancer cells to invade the perineurium, a great deal of evidence suggests that NGF may directly induce hypersensitivity in sensory neurons in both in vitro and in vivo models of neuropathic pain $[22,23]$.

Sarcoma cells have been known for almost 50 years to produce and secrete NGF [24], and in fact, the molecule was originally discovered in experiments with sarcoma cells $[25,26]$. The experience with NGF expression in nerve sheath tumors is much more limited, but it seems reasonable to hypothesize that NGF might be secreted by MPNST's. More investigation is needed to further investigate this issue.

\section{Significance of the Schwann cell lineage to tumor- associated neuropathic pain}

A large body of published work supports the notion that Schwann cells are involved in a number of dynamic interactions with their associated axons, many of which can promote (or in some cases inhibit) the development of neuropathic pain in the setting of neuronal injury. This is of special significance to the present discussion given that a significant number of peripheral nerve tumors are of Schwann cell lineage, and in theory, the disinhibition or loss of Schwann cell functions could also play a role in the production of neuropathic pain.

Schwann cells produce a number of cytokines in response to injury, many of which have been implicated in the development of neuropathic pain in the injured peripheral nerve. For example, normal Schwann cells have been found to increase expression of Tumor necrosis factoralpha (TNF-a) in response to ex vivo compressive injury [27], and sub-endoneureal TNF-a injection in vivo induces neuropathic pain in rats [28]. Similar lines of evidence implicate Schwann cell production of matrix metalloproteinase-9 (MMP9) [29], cyclooxgenase-2 [30], and cytokines $[31,32]$ in development of neuropathic pain.

Conversely, Schwann cells play a critical role in guidance of sprouting axons during neuronal regeneration. Regenerating neurons which lack functional Schwann cell guidance, often sprout in random directions and fail to form functional connections, which some investigators hypothesize may spontaneously fire causing neuropathic pain $[33,34]$. It is unclear whether this dysfunctional sprouting occurs in the setting of Schwann cell neoplasia, however it is reasonable to hypothesize that these cells likely are atleast less than ideal cellular guideposts for regenerating neurons. 
While little published work has focused on the occurrence of either phenomenon in peripheral nerve tumor, either seems like a reasonable starting point for further investigation in this area.

\section{Conclusion}

Some form of pain is seen in most patients with peripheral nerve tumor, regardless of their histopathology. However, careful delineation of the nature and character of the pain seems to provide valuable information for planning the surgical approach to these tumors. Lesions with a significant degree of rest pain should be considered as potentially malignant in terms of pre-surgical planning. Additionally, a better understanding of the chemical and molecular causes of pain in these lesions will likely lead to increased therapeutic options for palliating pain from tumors involving and invading peripheral nerves.

\section{Authors' contributions}

MS wrote substantial portion of manuscript. JL contibuted significant portion of ideas, especially section on mechanisms of neuropathic pain. NMB concept conception, wrote significant portion of manuscript.

\section{References}

I. Ogose A, Hotta T, Morita T, Yamamura S, Hosaka N, Kobayashi H, Hirata $Y$ : Tumors of peripheral nerves: correlation of symptoms, clinical signs, imaging features, and histologic diagnosis. Skeletal radiology 1999, 28(4): 183-188.

2. Kim DH, Murovic JA, Tiel RL, Kline DG: Operative outcomes of 546 Louisiana State University Health Sciences Center peripheral nerve tumors. Neurosurgery clinics of North America 2004, I5(2): 177-192.

3. Valeyrie-Allanore L, Ismaili N, Bastuji-Garin S, Zeller J, Wechsler J, Revuz J, Wolkenstein P: Symptoms associated with malignancy of peripheral nerve sheath tumours: a retrospective study of 69 patients with neurofibromatosis I. The British journal of dermatology 2005, I 53(I):79-82.

4. Kim DH, Murovic JA, Tiel RL, Kline DG: Management and outcomes in 318 operative common peroneal nerve lesions at the Louisiana State University Health Sciences Center. Neurosurgery 2004, 54(6): | 42 I-8; discussion |428-9.

5. Fein DA, Lee WR, Lanciano RM, Corn BW, Herbert SH, Hanlon AL, Hoffman JP, Eisenberg BL, Coia LR: Management of extremity soft tissue sarcomas with limb-sparing surgery and postoperative irradiation: do total dose, overall treatment time, and the surgery-radiotherapy interval impact on local control? International journal of radiation oncology, biology, physics 1995, 32(4):969-976.

6. Leroy K, Dumas V, Martin-Garcia N, Falzone MC, Voisin MC, Wechsler J, Revuz J, Creange A, Levy E, Lantieri L, Zeller J, Wolkenstein $P$ : Malignant peripheral nerve sheath tumors associated with neurofibromatosis type I: a clinicopathologic and molecular study of 17 patients. Archives of dermatology 200I, 137(7):908-9|3.

7. Mundt AJ, Awan A, Sibley GS, Simon M, Rubin SJ, Samuels B, Wong W, Beckett M, Vijayakumar S, Weichselbaum RR: Conservative surgery and adjuvant radiation therapy in the management of adult soft tissue sarcoma of the extremities: clinical and radiobiological results. International journal of radiation oncology, biology, physics 1995, 32(4):977-985.

8. Devor M, Govrin-Lippmann R, Angelides K: Na+ channel immunolocalization in peripheral mammalian axons and changes following nerve injury and neuroma formation. I Neurosci 1993, 13(5):1976-1992.
9. Gold MS, Weinreich D, Kim CS, Wang R, Treanor J, Porreca F, Lai J: Redistribution of $\mathrm{Na}(\mathrm{V}) \mathrm{I} .8$ in uninjured axons enables neuropathic pain. J Neurosci 2003, 23(I): I58-166.

10. Koschorke GM, Meyer RA, Tillman DB, Campbell JN: Ectopic excitability of injured nerves in monkey: entrained responses to vibratory stimuli. Journal of neurophysiology 1991, 65(3):693-70 I.

II. Michaelis M, Blenk KH, Vogel C, Janig W: Distribution of sensory properties among axotomized cutaneous $C$-fibres in adult rats. Neuroscience 1999, 94(I):7-10.

12. Coward K, Plumpton C, Facer P, Birch R, Carlstedt T, Tate S, Bountra C, Anand P: Immunolocalization of SNS/PN3 and NaN/SNS2 sodium channels in human pain states. Pain 2000, 85(I2):4I-50.

13. Yiangou Y, Birch R, Sangameswaran L, Eglen R, Anand P: SNS/PN3 and SNS2/NaN sodium channel-like immunoreactivity in human adult and neonate injured sensory nerves. FEBS letters 2000, 467(2-3):249-252.

14. Yiangou Y, Facer P, Birch R, Sangameswaran L, Eglen R, Anand P: $P 2 X 3$ receptor in injured human sensory neurons. Neuroreport 2000, II(5):993-996.

15. Roza C, Laird JM, Souslova V, Wood JN, Cervero F: The tetrodotoxin-resistant $\mathrm{Na}+$ channel Navl.8 is essential for the expression of spontaneous activity in damaged sensory axons of mice. The Journal of physiology 2003, 550(Pt 3):921-926.

16. Sevcik MA, Ghilardi JR, Peters CM, Lindsay TH, Halvorson KG, Jonas BM, Kubota K, Kuskowski MA, Boustany L, Shelton DL, Mantyh PW: Anti-NGF therapy profoundly reduces bone cancer pain and the accompanying increase in markers of peripheral and central sensitization. Pain 2005, II 5(I-2):|28-|4|.

17. Wacnik PW, Baker CM, Herron MJ, Kren BT, Blazar BR, Wilcox GL, Hordinsky MK, Beitz AJ, Ericson ME: Tumor-induced mechanical hyperalgesia involves CGRP receptors and altered innervation and vascularization of DsRed2 fluorescent hindpaw tumors. Pain 2005, II 5( I-2):95-106.

18. Zhu Z, Friess H, diMola FF, Zimmermann A, Graber HU, Korc M, Buchler MW: Nerve growth factor expression correlates with perineural invasion and pain in human pancreatic cancer. Clin Oncol 1999, 17(8):2419-2428.

19. Wacnik PW, Eikmeier LJ, Ruggles TR, Ramnaraine ML, Walcheck BK, Beitz AJ, Wilcox GL: Functional interactions between tumor and peripheral nerve: morphology, algogen identification, and behavioral characterization of a new murine model of cancer pain. J Neurosci 200I, 2 I (23):9355-9366.

20. Lee PR, Cohen JE, Tendi EA, Farrer R, GH DEV, Becker KG, Fields RD: Transcriptional profiling in an MPNST-derived cell line and normal human Schwann cells. Neuron Glia Biol 2004, I(2): $135-147$

21. Halvorson KG, Kubota K, Sevcik MA, Lindsay TH, Sotillo JE, Ghilardi JR, Rosol TJ, Boustany L, Shelton DL, Mantyh PW: A blocking antibody to nerve growth factor attenuates skeletal pain induced by prostate tumor cells growing in bone. Cancer research 2005 , 65(20):9426-9435.

22. Anand $P$ : Neurotrophic factors and their receptors in human sensory neuropathies. Progress in brain research 2004, I 46:477-492.

23. Kitamura N, Konno A, Kuwahara T, Komagiri Y: Nerve growth factor-induced hyperexcitability of rat sensory neuron in culture. Biomedical research (Tokyo, Japan) 2005, 26(3): I23-130.

24. Werrbach-Perez K, Perez-Polo JR: De novo synthesis of NGF subunits in S-180 mouse sarcoma cell line. Neurochemical research 1987, I 2(10):875-883.

25. Cohen S, Levi-Montalcini R, Hamburger V: A Nerve Growth-Stimulating Factor Isolated from Sarcom as $\mathbf{3 7}$ and $\mathbf{1 8 0}$. Proceedings of the National Academy of Sciences of the United States of America 1954, 40(10): 1014-1018

26. Levi-Montalcini $\mathrm{R}$, Meyer $\mathrm{H}$, Hamburger $\mathrm{V}$ : In vitro experiments on the effects of mouse sarcomas 180 and 37 on the spinal and sympathetic ganglia of the chick embryo. Cancer research 1954, I 4(I):49-57.

27. Wagner R, Myers RR: Schwann cells produce tumor necrosis factor alpha: expression in injured and non-injured nerves. Neuroscience 1996, 73(3):625-629.

28. Wagner R, Myers RR: Endoneurial injection of TNF-alpha produces neuropathic pain behaviors. Neuroreport 1996, 7(18):2897-290।. 
29. Chattopadhyay S, Myers RR, Janes J, Shubayev V: Cytokine regulation of MMP-9 in peripheral glia: Implications for pathological processes and pain in injured nerve. Brain Behav Immun 2006.

30. Takahashi M, Kawaguchi M, Shimada K, Konishi N, Furuya H, Nakashima T: Cyclooxygenase-2 expression in Schwann cells and macrophages in the sciatic nerve after single spinal nerve injury in rats. Neuroscience letters 2004, 363(3):203-206.

31. Bhangoo SK, Ren D, Miller RJ, Chan DM, Ripsch MS, Weiss C, McGinnis C, White FA: CXCR4 chemokine receptor signaling mediates pain hypersensitivity in association with antiretroviral toxic neuropathy. Brain Behav Immun 2007.

32. Abbadie C, Lindia JA, Cumiskey AM, Peterson LB, Mudgett JS, Bayne EK, DeMartino JA, Maclntyre DE, Forrest MJ: Impaired neuropathic pain responses in mice lacking the chemokine receptor CCR2. Proceedings of the National Academy of Sciences of the United States of America 2003, I 00(13):7947-7952.

33. Koltzenburg M, Scadding J: Neuropathic pain. Current opinion in neurology 200I, I 4(5):64I-647.

34. Tyner TR, Parks N, Faria S, Simons M, Stapp B, Curtis B, Sian K, Yamaguchi KT: Effects of collagen nerve guide on neuroma formation and neuropathic pain in a rat model. American journal of surgery 2007, 193(I):el-6.

Publish with Biomed Central and every scientist can read your work free of charge

"BioMed Central will be the most significant development for disseminating the results of biomedical research in our lifetime. "

Sir Paul Nurse, Cancer Research UK

Your research papers will be:

- available free of charge to the entire biomedical community

- peer reviewed and published immediately upon acceptance

- cited in PubMed and archived on PubMed Central

- yours - you keep the copyright

Submit your manuscript here:

http://www.biomedcentral.com/info/publishing_adv.asp
BioMedcentral 